\title{
PENGARUH BUDAYA MOOI INDIË DAN RIJSTTAFEL PADA DESAIN SAMPUL BUKU RESEP MASAKAN
}

\author{
Viki Restina Bela \\ Mahasiswa Program Studi Desain Komunikasi Visual \\ Pascasarjana ISI Yogyakarta \\ restinabelaviki@gmail.com
}

\begin{abstract}
The Dutch colonial occupation of the archipelago had a big influence on the growth and development of culture in society. Social, political, economic and cultural conditions are closely related which influence each other. In the 19th century, amidst the rapid economic development of the Dutch East Indies government, there was a large migration of Europeans to the colonial lands. This led to the emergence and development of Indis culture. Mooi Indie in the arts and rijsttafel in the culinary world is a form of Indis culture. Both were major factors in the rapid development of Indis culture. Various media are used to spread this culture, including one of them is a cookbook cover design. Cuisine and food as basic human needs become a medium for acculturation, therefore the emergence of cookbooks is one way to see the cultural influences that are formed in society. Researchers use historical methods in this qualitative research, through a process of searching, selection, criticism, then analysis and interpretation. As a result, visual elements such as stately houses, coconut trees, and exotic landscapes in the style of a tropical country from Mooi Indië's painting style are found on the cover designs of the cookbooks. Likewise, the presentation of food using plates arranged in a buffet style then brought by dark-skinned waiters on the cover of the cookbook, indicating that the rijsttafel also influenced the choice of cover designs that represented its era.
\end{abstract}

Keywords: Cover Designs, Cookbook, Mooi Indië, Rijsttafel

\section{PENDAHULUAN}

Perkembangan dan pertumbuhan parktik desain memiliki kaitan erat dengan perkembangan dan pertumbuhan masyarakat, di dalamnya termasuk kondisi sosial, politik dan ekonomi yang sedang berlangsung. Pendudukan kolonial Belanda membawa pengaruh kuat pada perkembangan budaya di Nusantara dalam berbagai aspek, dari seni rupa sampai budaya makan. Persentuhan budaya Barat dengan Pribumi yang terjadi kemudian memberikan gambaran kondisi masyarakat pada masa itu. Kehadiran kolonial Belanda di Nusantara membawa serta gaya desain Eropa yang kemudian tumbuh mewarnai tampilan penerbitan. Hal ini tidak dapat dihindari mengingat seorang perancang visual mendapat banyak pengaruh dari lingkungannya yang kemudian akan tercermin dalam hasil rancangannya.

Kolonialisme bangsa Barat cukup memberi andil besar pada pembentukan kebudayaan di Hindia Belanda. Pada tahun 1977, di akhir masa kekuasaan VOC, menjadi fase penanda perubahan sosial budaya yang mulai terbentuk pada awal abad ke-19. Meningkatnya kesejahteraan Eropa di wilayah koloni memengaruhi kehidupan sosial mereka yang menetap, terutama di Hindia Belanda. Banyak dari orang-orang Belanda yang menetap di Hindia Belanda datang dari kelas sosial rendah di negerinya. Namun ketika di 
Hindia Belanda, mereka menjadi golongan sosial teratas sehingga memerlukan suatu penyeimbang dengan bertingkah laku serba Eropa (Rahman, 2016:13).

Salah satu sisi Eropa yang ditonjolkan pada masa itu yakni aktivitas kesenian. Seni rupa, khususnya seni lukis pada abad ke-19 mulai menunjukkan eksistensinya dengan datangnya pelukis-pelukis Eropa ke Hindia Belanda. Pameran seni lukis mulai menjamur, membawa dan memperkenalkan bentuk-bentuk visual Barat. Pada abad itu, estetika romantik yang memiliki kecenderungan visual berupa pemandangan dengan sifat personifikasinya sedang berkembang. Karakter visual tersebut kemudian membentuk sebuah gaya lukisan yang dapat mewakili imajinasi mereka terhadap negara tropis. Mereka merekam keindahan alam dan eksotisme orang-orang Pribumi yang dikenal sebagai karya lukisan dengan tema Mooi Indië (Burhan, 2008:2736).

Mooi Indië yang secara harafiah berarti Hindia Indah merupakan pandangan Kolonial Belanda yang takjub kepada pemandangan Hindia Belanda pada masa itu. Selain Mooi Indië, hadir pula kebudayaan Indis lain yang populer pada saat itu, rijsttafel. Secara harafiah, rijst berarti nasi, dan tafel berarti meja, disatukan menjadi "hidangan meja" yang kemudian oleh orangorang Belanda disebut sebagai jamuan hidangan Indonesia yang ditata komplet di atas meja makan (Ganie dalam Rahman, 2016: 2). Budaya makan menggunakan jari tangan, tanpa piring sebagai alas makan, dan duduk bersila di lantai yang berkembang pada pribumi menjadi alasan hadirnya rijsttafel. Orang-orang Belanda yang melihat budaya tersbut sebagai budaya rendah tidak ingin terpengaruh dan membawa budaya Eropa yang lebih beradab. Mereka mulai memadukan penggunaan alat makan seperti sendok, garpu, piring, meja dan kursi. Rahman (2016:4) mengatakan bahwa Rijsttafel menjadi sebuah cara pandang dan cara kemas hidangan Pribumi yang membuatnya menjadi populer.

Meningkatnya jumlah orang Eropa yang tiba di Hindia Belanda pasca pembukaan Terusan Suez lambat laun memengaruhi perubahan sosial. Kehadiran aliran seni lukis Mooi Indië dan budaya makan rijsttafel sebagai akibat terjadinya akulturasi budaya yang tak dapat dihindari. Pengaruh akulturasi budaya ini tak hanya terjadi satu arah melainkan keduanya, baik bagi orang Belanda maupun orang Pribumi, mereka sama-sama menyerap dan memengaruhi satu sama lain. Sebagaimana dikatakan Koentjoroningrat (1990:248) dalam Pengantar Antropologi, akulturasi merupakan proses sosial yang timbul bila suatu kelompok manusia dengan suatu kebudayaan tertentu dihadapkan pada unsurunsur dari suatu kebudayaan asing yang sedemikian rupa. Sehingga unsur-unsur kebudayaan asing tersebut lambat laun diterima dan diolah ke dalam kebudayaan asli tanpa menyebabkan hilangnya kepribadian kebudayaan itu sendiri.

Persentuhan budaya Belanda dengan Pribumi saat itu cukup memengaruhi kemunculan buku-buku resep masakan. Pada awalnya, orang Belanda yang datang ke Hindia Belanda tak dapat menyesuaikan selera makannya, di sinilah para nyai yang mereka kawini mengambil peranan besar. Pun bagi pejabat tinggi, urusan dapur diserahkan kepada koki walaupun mereka membawa serta istri mereka datang ke Hindia Belanda. Istri pejabat Belanda ini kemudian belajar menyerap masakan pribumi, yang kemudian beberapa di 
antaranya menerbitkan buku resep masakan. Buku-buku yang terbit pada masa itu pun dikemas dengan sampul buku yang sedemikian rupa. Kehadiran pengaruh aliran seni lukis Mooi Indië dan budaya makan rijsttafel yang kental dapat dirasakan pada desain sampul buku-buku resep masakan. Buku-buku resep masakan yang terbit pada masa itu diantaranya Ons Huis in Indie (1908), Makanlah Nasi! (Eet Rijst!) De Indische Rijsttafel (voor Holland) (1922), Groot nieuw volledig Indisch kookboek (1925), Onze Rijzttafel (t.th), Het Geheim van de Rijsttafel (1934), dan lainnya.

Pengkajian ini merupakan penelitian kualitatif dengan menggunakan metode sejarah. Melalui proses pencarian, seleksi, dan kritik, kemudian analisis dan interpretasi dari sumbersumber tersebut sampai pada penulisan historiografi. Dengan menggunakan teori fungsionalisme struktural Talcott Parson, dikatakan bahwa realitas sosial sebagai hubungan sistem: sistem masyarakat, yang berada dalam keseimbangan, yakni kesatuan yang terdiri dari bagian-bagian yang saling tergantung, sehingga perubahan satu bagian dipandang menyebabkan perubahan lain dari sistem. Dalam hal ini, dasar-dasar perubahan sosial dapat terjadi karena penyesuaianpenyesuaian yang dilakukan oleh sistem sosial terhadap perubahan-perubahan yang datang dari luar, pertumbuhan yang melalui proses diferensiasi struktural dan fungsional dan penemuan-penemuan baru oleh anggota Perubahan kebijakan ekonomi liberal setelah 1870 membawa perubahan besar pada sistem sosial masyarakat. Kebijakan tersebut berdampak pada pesatnya pertumbuhan ekonomi Hindia Belanda. Berdirinya pabrik dan perkebunan mendorong kebutuhan pada tenaga kerja terampil yang murah (Sitompul, 2015). Hal inilah yang kemudian mendorong pemerintah kolonial membuka akses pendidikan bagi bumiputera. Terbukanya akses pendidikan bagi bumiputera kemudian memunculkan fungsi-fungsi baru dalam masyarakat. Fungsi baru yang menjadi wujud kualitas perseorangan dalam struktur sosial juga terjadi pada lingkup kesenian yang kemudian menumbuhkan profesi pelukis, penulis hingga perancang, yang dalam hal ini termasuk perancang sampul buku.

\section{PEMBAHASAN}

Persentuhan kebudayaan Barat dengan Pribumi di Hindia Belanda sudah dimulai sejak abad ke-16. Meskipun aktivitasnya tersegmentasi secara sosial, politik, dan ekonomi, namun pada abad ke-19 silang budaya antar keduanya mulai mewujud yang kemudian dikenal dengan istilah kebudayaan Indis. Setelah tahun 1870, pemerintah kolonial Belanda memberlakukan kebijakan politik ekonomi liberal, begitu juga dengan keadaan ekonomi di Barat mengalami kemajuan seperti dibukanya terusan Suez yang mempersingkat perjalanan menuju tanah jajahan. Hal tersebut menyebabkan populasi orang Eropa di Hinda Belanda meningkat.

Pulau Jawa sebagai tujuan utama orang-orang Eropa, khususnya Belanda, mulai menampakkan pertumbuhan ekonominya dengan pembangunan gedunggedung modern. Salah satunya gedung kesenian Bataviasche Kunstkring yang mengelola seni pertunjukan dan seni rupa dari Eropa. Kesenian menjadi salah satu aspek untuk menyalurkan gaya hidup kelas atas dari kebudayaan Indis. Pelukis yang berpameran di gedung Bataviasche Kunstkring juga dibatasi pada pelukispelukis Eropa. Karya-karya mereka banyak menggambarkan keindahan-keindahan 
alam yang dihiasi gunung, sawah, pepohonan, bunga, pantai, pohon kelapa, dengan suasana romantis seperti di surga, tenang, dan damai. Semua penggambaran tersebut merujuk pada sebuah istilah yang disebut Mooi Indië yaitu Hindia Belanda yang indah (Burhan, 2008:17, 35-36).

Percampuran budaya yang terjadi pada masa kolonial Belanda juga terjadi di atas meja makan. Budaya makan di masa kolonial tersebut dikenal dengan istilah rijsttafel, jamuan hidangan yang ditata komplet di atas meja makan. Budaya makan ini sendiri terbentuk karena kolonial Belanda tidak ingin disamakan dengan para pribumi yang makan tanpa alat dan alas, mereka lalu membawa cara makan pribumi ke atas meja makan dan menggunakan alat makan lengkap. Kebiasaan makan merupakan salah satu bentuk dari gaya hidup, yang mana gaya hidup dalam perspektif sejarah dikatakan Sartono Kartodirjo (1992 : 200-201) mencerminkan status, peranan, kekuasaan dan keterampulan para pendukung gaya hidup tersebut. Perihal kebiasaan makan tersusun oleh beberapa hal (Hammond, 1971); apa makanan yang sebaiknya dimakan, kombinasi makanan yang pantas, waktu yang pantas untuk makan, peralatan yang tepat digunakan, dan tata penyajian yang baik.

Pesatnya kedatangan Belanda merupakan dampak adanya perubahan kebijakan dan dibukanya terusan Suez yang mampu mempercepat perpindahan penduduk Belanda ke tanah koloni. Banyak diantara penduduk Belanda yang datang ke Hindia Belanda datang dari kelas bawah di negara asalnya yang tak memungkinkan mereka untuk turut serta membawa istrinya.
Sulitnya menyesuaikan selera makan dengan kondisi di Hindia Belanda mendorong para koloni ini untuk menyerahkan urusan dapur kepada nyai yang mereka kawini. Para pejabat yang membawa istrinya pun turut mempekerjakan koki untuk urusan dapur. Tidak hanya untuk urusan dapur, kehidupan mewah, yang berbeda dengan kehidupan awal, ketika mereka pindah ke Hindia Belanda mereka membangun rumah besar, pekarangan luas, keberadaan pelayan pribumi, sampai pesta dan resepsi dengan makanan yang melimpah. Tidak seperti kebudayaan Tiongkok, Perancis, dan Italia yang memiliki tradisi kuliner adiluhung, kebiasaan makanan Pribumi kemudian dikemas untuk memenuhi gaya hidup orang-orang Eropa. Melalui rijsttafel, pandangan mengenai kebiasaan makan Pribumi dan perubahan wacananya dimodifikasi secara Barat melaui sentuhan moral, etika, estetika, dan penunjuk status sosial dalam kehidupan masyarakat kolonial (Rahman, 2016:2-8). Terbentuknya budaya baru ini seperti yang dikatakan Fadly Rahman (2011: 10) mencerminkan bagaimana kebudayaan Indis saling membutuhkan, tergantung dan saling menghidupi antarkeduanya (symbiotic relation) (Rahman, 2011).

Kehadiran kolonial Belanda di Indonesia pun memunculkan buku resep masakan Nusantara dengan sentuhan Eropa. Dikutip dalam peluncuran buku Rasa Nusantara, Fadly mengatakan "Tapi, sebenarnya langka itu bukan berarti tidak ada sumber. Sumber sejarah kita, teks serat misalnya, memang implisit sifatnya. Tetapi, sebenarnya serat itu lebih kaya nuansa. Karena selain peristiwa ia juga merekam suasana. Itu yang tidak ditemukan dalam sumber Barat," Hal ini menunjukkan perbedaan dari budaya menulis di Indonesia. Dengan kehadiran kolonial Belanda, penulisan resep masakan pun mengalami perubahan, 
termasuk penyesuaian resep yang didominasi oleh unsur pribumi namun tetap mendapat sentuhan Eropa. Buku-buku resep masakan yang kemudian muncul pada masa kolonial itu terdiri dari bagaimana masakan dibuat, dihidangkan, tata cara makan dan penggunaan alat-alat pendukungnya. Hal ini turut serta menggambarkan bagaimana perubahaan kebiasaan yang terjadi akibat asimilasi kebudayaan, disamping itu pula, budaya makan tersebut menjadi alat dalam kebudayaan Indis untuk memperlihatkan status sosialnya.

Penyebaran budaya Eropa tidak terbatas melalui Mooi Indie ataupun risjttafel, buku resep masakan yang muncul juga menjadi media penyebaran budaya. Apa yang tampak pada muka buku resep masakan yang terbit pula menggambarkan isi dari buku tersebut. Buku resep masakan ini pun secara langsung maupun tidak memberikan gambaran bagaimana kehidupan rumah tangga dan kebiasaan yang terbentuk pada masyarakat pada masanya. Budaya yang hidup di masyarakat dapat dilihat melalui resep masakan, penggunaan piranti makanan, dan cara konsumsi masyarakat

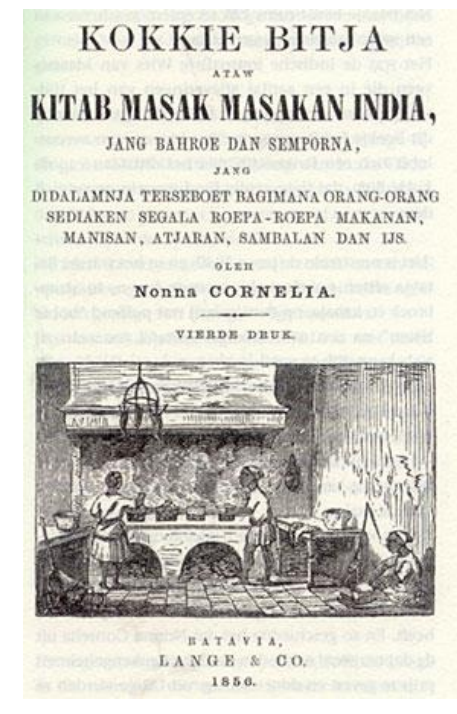

Gambar 1 Desain sampul Kokki Bitja, disusun oleh Cornelia, 1857.
Sumber:

https://www.nitroburner.nl/salindo_com/koken/b itja.htm

Buku masak yang terbit pertama kali tahun 1857 berjudul Kokki Bitjia atau Kitab Masak-Masakan India yang Bahroe dan Sempoerna. Buku yang disusun oleh Cornelia ini berisi kumpulan resep masakan yang dapat diolah di Hindia. Secara isi, buku ini berisikan resep tradisional yang telah disesuaikan. Namun, secara visual, pada sampul buku tersebut tidak tampak pengaruh Mooi Indië yang khas yakni keindahan eksotis Hindia Belanda yang muncul. Tampilan muka buku ini masih terlihat sederhana. Begitu pula dengan jejak risjttafel yang tidak muncul, yang muncul adalah gambaran dapur pada masa itu.

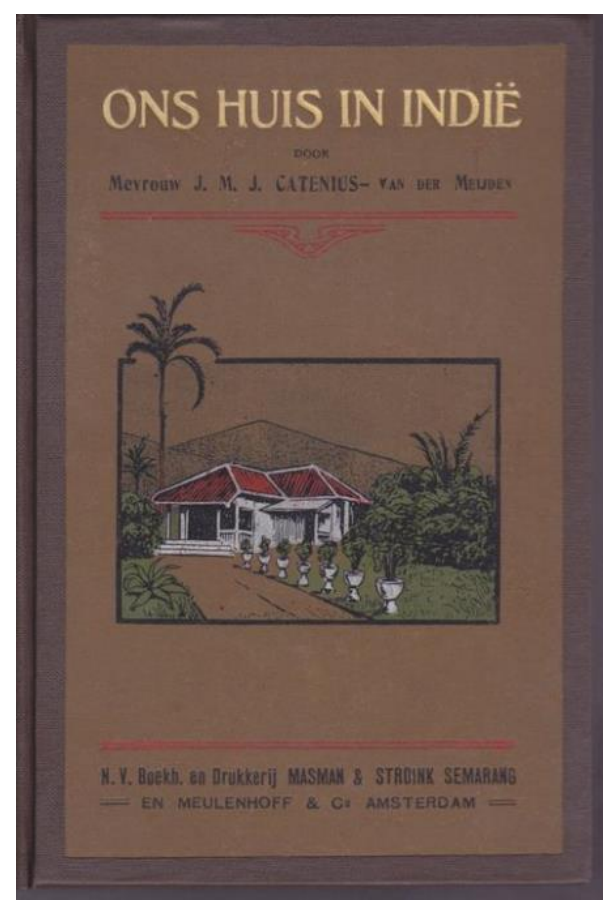

Gambar 2 Desain sampul Ons Huis in Indie, ditulis oleh Cantenius-van der Meijden, 1908. Sumber:

https://auction.catawiki.com/kavels/6849615indonesia-m-j-catenius-van-der-meijden-ons-huisin-indie-handbook-1908, diakses 19 Desember 2019. 
Tren saintifikasi mulai berkembang di awal abad ke-20 (Rahman, 2017:7), seorang gastronom Catenius-van der Meijden mendalami pengetahuan mengenai makanan di Hindia. Pada masa ini, gambaran mengenai keindahan Hindia Belanda (Mooi Indië) mulai memengaruhi bentuk muka buku resep masakan yang terbit. Ons Huis in Indië (rumah kita di Hindia) karya Cateniusvan der Meijden terbit pada tahun 1908. Desain sampulnya menggambarkan kemegahan rumah orang Belanda di Hindia. Bangunan megah, dikelilingi pekarangan luas, dengan kesejukan dari pohon kelapa dan rerumputan di sekitar serta suasana yang tampak tentram. Selain itu, Cantenius juga menerbitkan buku lagi pada tahun 1925, berjudul Groot nieuw volledig Indisch kookboek (buku masak Hindia terbesar, terbaru, dan terlengkap). Desain sampulnya menggambarkan seorang perempuan Eropa yang sedang sibuk memasak. Dapat dilihat dari penampilannya yang menggunakan pakaian terusan (dress) dengan celemek atau apron, dan rambut pendek yang ditata rapi. Pada buku kedua ini, dapat dilihat pula bagaimana perpaduan antara budaya pribumi dan Eropa bertemu. Dapat dilihat, ada siluet seorang perempuan dengan gelungan rambut yang khas konde, menggambarkan bagaimana koki pribumi menjadi latar belakang munculnya resepresep yang ada.

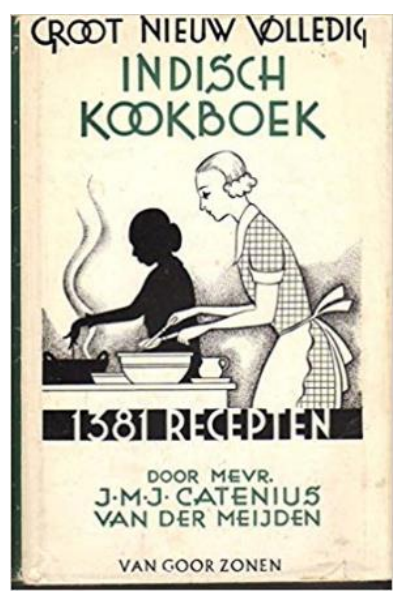

Gambar 3 Desain sampul Groot nieuw volledig Indisch kookboek, ditulis oleh Cantenius-van der Meijden, 1925.

Sumber: https://www.amazon.com/Oost-IndischVolledige-Rijsttafel-Belangrijk-

Aanhangsel/dp/B0073HSSI4, diakses 19 Desember 2019.

Buku resep masakan berikutnya Onze Rijsttafel disusun oleh E.W.K. Steinmetz yang tidak diketahui kapan terbitnya. Desain sampul pada buku ini menggambarkan seorang pramusaji atau pelayan dengan warna kulit yang lebih gelap yang dapat dilihat sebagai penggambaran pribumi. Gambaran ini menunjukkan posisi pribumi yang dianggap lebih rendah karena pekerjaannya yang melayani orang-orang Belanda. Kehadiran pelayan pada masa itu dapat menjadi tolak ukur martabat atau kelas sosial keluarga yang dilayani. Semakin banyak jumlah pelayan yang dimiliki, semakin tinggi pula kelas sosialnya.

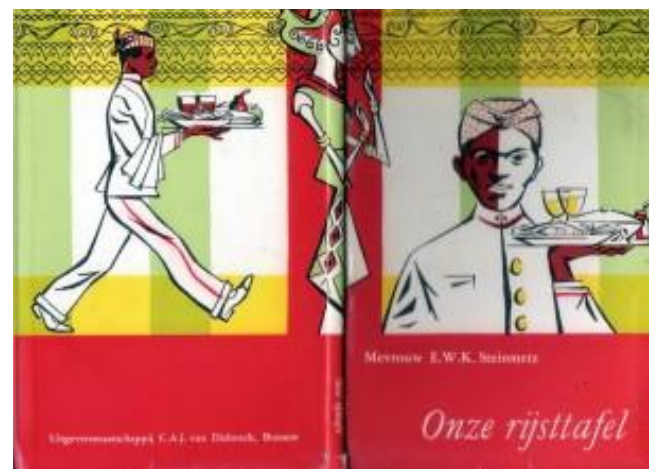


Gambar 4 Desain sampul Onze Rijzttafel, disusun oleh E.W.K. Steinmetz

Sumber:

https://www.kompasiana.com/detikhidup/55005 6b28133119f19fa7701/selayang-pandang-sejarahbudaya-makan-rijsttafel, diakses 19 Desember 2019.

Memasuki tahun 1930-an, kondisi ekonomi Belanda mengalami masa krisis. Kesadaran kaum intelek pribumi mulai menunjukkan eksistensinya. Seperti para pelukis Pribumi mulai membentuk sebuah kelompok untuk bergerak bersama menciptakan jalan bagi kesenian Indonesia, maka dibentuklah Persagi yaitu Persatuan Ahli Gambar Indonesia yang digagas oleh Sudjojono pada tahun 1938. Setahun sebelumnya, yaitu 1937 muncul Dr. Poorwo Soedarmo menjadi penggagas berdirinya Lembaga Makanan Rakjat.

Gerakan-gerakan kaum Pribumi tersebut tentu saja mempengaruhi perkembangan seni lukis dan budaya makan Indonesia. Mereka mulai mengkritisi Mooi Indië maupun rijsttafel dengan caranya masing-masing. Dalam seni lukis, mereka membawa semangat realisme kondisi sosial yang perlu dilukiskan, tidak melulu keindahan-keindahannya saja. Kritik yang dilontarkan oleh Sudjojono mengenai Mooi Indië ini hanya menggambarkan yang serba molek, serba indah dan melenakan dari kondisi sesungguhnya yakni kondisi terjajah. Sudjojono melihat Mooi Indië ini merupakan bentuk yang digunakan hanya untuk menghibur orang-orang asing. Sedangkan dalam hal makanan, mulai muncul dan ditempatkan ke dalam ruang pers pribumi. Munculnya bukubuku resep masakan yang disusun Pribumi tidak saja mengimbangi karya orang Belanda, bahkan mereka mulai berani menandinginya.

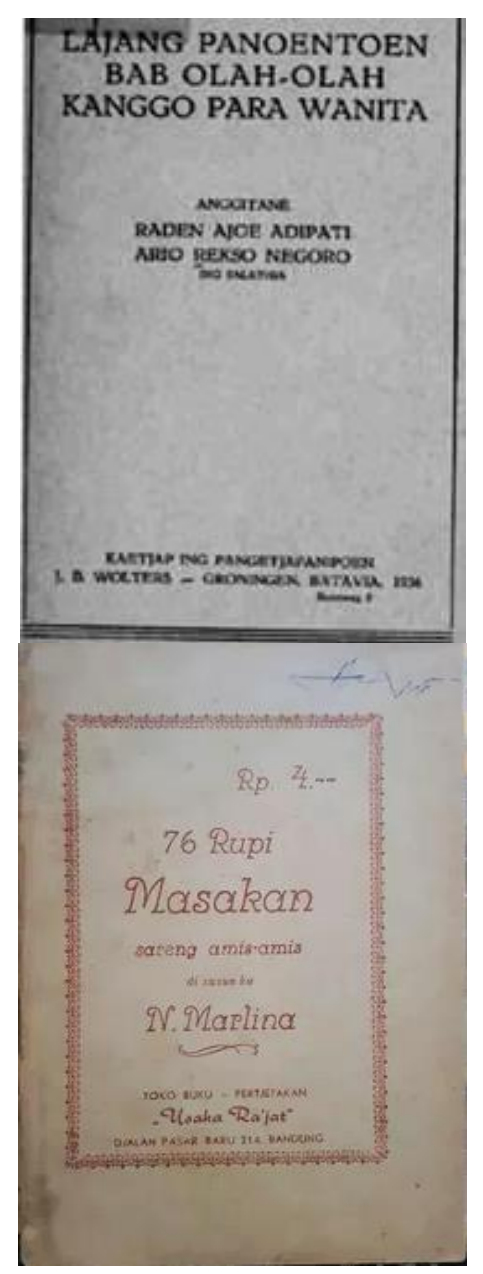

Gambar 5 Atas: desain sampul “Lajang Panoentoen Bab Olah-Olah Kanggo para Wanita", ditulis oleh R.A.Kardinah, 1936. Bawah: desain sampul "Masakan Sareng Amis-Amis", 1934. Sumber: https://docplayer.info/95527353Kuliner-di-indonesia.html, https://www.bukalapak.com/p/hobikoleksi/buku/masak/fm3tix-jual-n-marlina-76rupi-masakan-sareng-amis-amis, diakses 19 Desember 2019.

Pada tahun 1936, Raden Ajoe Adipati Arija Reksa-Nagara alias R.A. Kardinah (saudari R.A. Kartini), seorang gastronom didikan Eropa menerbitkan buku resep masakan yang berjudul "Lajang Panoentoen Bab Olah-Olah Kanggo para Wanita”. Balai Pustaka turut menerbitkan buku resep masakan dengan bahasa daerah, salah satu contohnya buku berbahasa Sunda "Masakan Sareng Amis-Amis" (masakan dan manis- 
manis) yang terbit pada tahun 1934. Desain sampulnya masih terlihat sederhana dengan elemen visual yang memainkan besar kecil huruf dan beberapa macam jenis huruf yang dipakai. Buku ini hadir tanpa menggunakan ilustrasi, yang terlihat hanyalah ornamen yang membingkai judul buku tersebut.

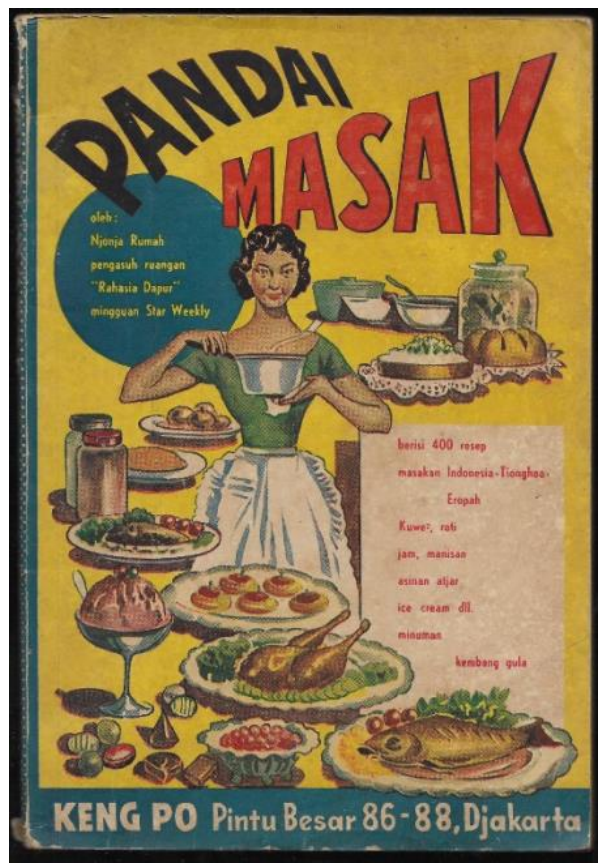

Gambar 6 Desain sampul "Pandai Masak", disusun oleh Julie Sutardjana, 1957.

Sumber: https://www.bukalapak.com/p/hobikoleksi/buku/masak/8ypkzz-jual-buku-pandaimasak, diakses 19 Desember 2019.

Seiring berakhirnya pendudukan kolonial Belanda di Hindia, kelompokkelompok yang dibentuk pada masa tersebut dibubarkan ketika Jepang datang. Kelesuan di banyak bidang mulai terasa, seperti seretnya aktivitas kesenian maupun perbukuan. Baru setelah Indonesia mendapatkan kemerdekaannya, semangat kelompok-kelompok tadi mulai dilanjutkan oleh generasi-generasi berikutnya. Pada tahun 1951, seorang peranakan Tionghoa, Julie Sutardjana, menjadi penanggungjawab rubrik Rahasia Dapur di majalah mingguan Star Weekly dengan nama pena Nyonya Rumah. Atas permintaan pembaca, kumpulan resep-resep tersebut dibukukan menjadi sebuah buku resep masakan "Pandai Masak", terbit tahun 1957. Desain sampulnya masih sangat terpengaruh dengan rijsttafel, tampak dari pakaian yang digambarkan bercirikan modern, hidangannya berupa makanan dan minuman Indonesia yang disajikan di atas piring dan gelas seperti budaya prasmanan. Namun, penggambaran ilustrasi wanita yang nampak tidak lagi terlihat sangat Eropa dengan menampilkan wanita dengan kulit sawo matang khas Asia Tenggara.

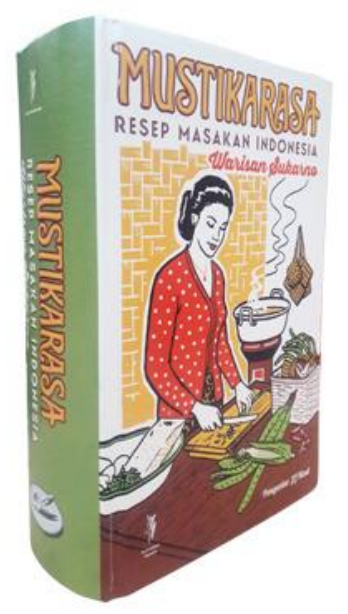

Gambar 7 Desain sampul "Mustika Rasa”,1967. Sumber:

https://www.thejakartapost.com/files/images2/2 4mustikasrasa.jpg

Pada tahun 1950-an Presiden Sukarno yang sedang gencar dengan program "revolusi makanan rakjat" kemudian menghasilkan sebuah buku resep masakan Indonesia "Mustika Rasa". Desain sampulnya mulai meninggalkan konsep Mooi Indië dan rijsttafel, perempuan yang digambarkan sesuai realitas orang Pribumi dengan 
pakaian kebaya dan rambut yang disanggul. Suasana sekelilingnya juga menggambarkan situasi dapur Pribumi dengan peralatan dan cara memasak tradisional. Judul buku pun menggunakan bentuk huruf dengan lengkung khas ukiran tradisional.

\section{KESIMPULAN}

Dari pemaparan di atas, dapat dilihat bahwa kondisi sosial suatu masyarakat dapat tergambarkan dalam banyak hal, mulai dari resep hingga desain sampul buku yang terbit. Seperti ungkapan yang muncul bagaimana perubahan budaya dapat dilihat dari perkembangan atau perbedaan satu resep masakan yang sama. Desain sampul buku pun dapat memberikan gambaran budaya yang tengah terbentuk. Perubahan sosial yang terjadi pada masa kolonial Belanda sampai masa kemerdekaan pun turut terekam dan tersebar melalui desain sampul buku yang muncul. Termasuk bagaimana kemudian budaya Indis, Mooi Indië dan rijsttafel disebarluaskan melalui medium desain buku resep masakan. Ide-ide yang disebarkan ini kemudian berdampak pada kemunculan gerakan nasionalis Pribumi,

Penggambaran kemegahan bangunan, keindahan panorama Hindia Belanda, keeksotisan negri tropis menjadi sudut pandang utama gaya lukisan Mooi Indië. Pun perkembangan dari ide 'keindahan' yang digadang-gadang oleh para kolonial Belanda memengaruhi bagaimana budaya makan, yang terangkum dalam rijsttafel di masyarakat. Makan tidak lagi perkara mengisi perut tetapi menjadi alat untuk menunjukkan kelas sosial. Hal-hal ini menunjukkan bagaimana kondisi sosial, ekonomi dan politik yang berlangsung memiliki pengaruh terhadap praktik desain.

\section{KEPUSTAKAAN}

[1] Burhan, M. Agus. 2008. Perkembangan Seni Lukis Mooi Indië sampai Persagi di Batavia, 1900-1942. Jakarta: Galeri Nasional Indonesia.

[2] Koentjaraningrat. 1990. Pengantar Ilmu Antropologi. Jakarta: Penerbit PT Rineka Cipta.

[3] Rahman, Fadly. 2016. Rijsttafel Budaya Kuliner di Indonesia Masa Kolonial 18701942. Jakarta: PT Gramedia Pustaka Utama.

[4] Rahman, Fadly. 2017. "Dari Indische Keuken ke Boga Indonesia 1857-1967", Mata Jendela, Edisi 2 - 2017.

[5] Sitompul, Martin. 2015. "Dari OSVIA Sampai IPDN, Riwayat Sekolah Birokrat", Historia.id 